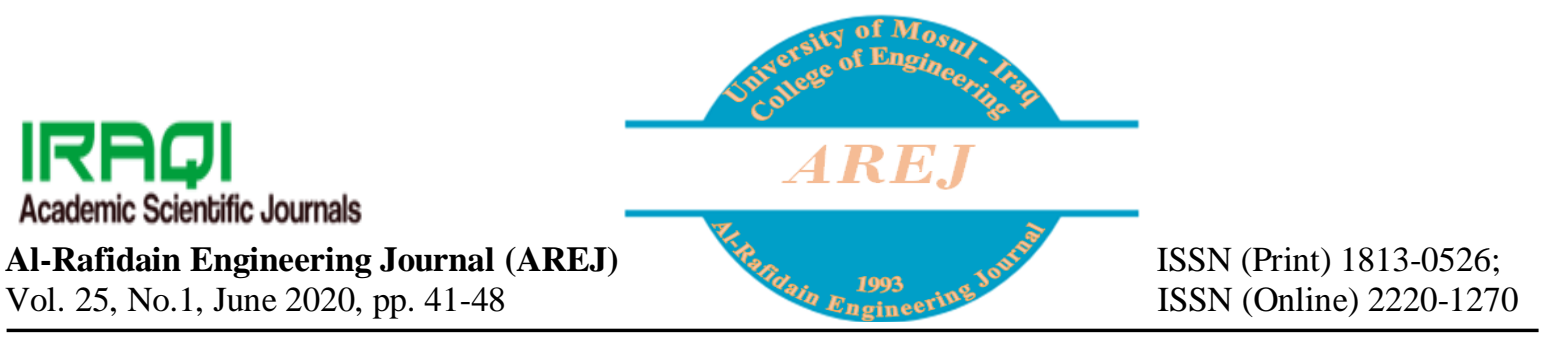

\title{
Comparative Rheological and Mechanical Characteristics of Different Warm-Mix Asphalt Additives Under Aging Conditions
}

\author{
Salim Abdullah Khalid \\ salim733132@gmail.com \\ Al-Hadidy AI \\ alhadidy@uomosul.edu.iq \\ Civil Engineering Departement, Collage of Engineering, University of Mosul
}

Received: 26/3/2020

Accepted: 16/5/2020

\begin{abstract}
This study compares the rheological and mechanical characteristics of three different kinds of warm-mix asphalt additives (WMAA) namely: natural zeolite (NZ), synthetic zeolite (SZ) and manufactured zeolite (MZ). 40/50 Dora penetration grade bitumen and one dosage of each WMAA were chosen. The resultant WMA binders were subjected to penetration, softening point, ductility, elastic recovery, Furol viscosity, elastic modulus, temperature susceptibility, aging, cracking index, compatibility, extensional viscosity, and shear strength tests. Test results depict that the rheological and mechanical characteristics of $N Z$ and $M Z$ binders are better than SZ binder against resistance to high and low temperature effects.
\end{abstract}

Keywords:

Rheological characteristics; Mechanical characteristics; Warm asphalt additives; Aging; Shear strength.

https://rengj.mosuljournals.com

Email: alrafidain_engjournall@uomosul.edu.iq

\section{INTRODUCTION}

Warm mix asphalt (WMA) technology was innovated in Europe to solve the environmental problems (minimize gases emissions) and to give several advantages such as: reduce plant emission and fumes, minimize consumption of energy and cost, enhance compaction and better workability, implementation in cold weather, minimized cracking due to thermal effects, minimize mixing and compaction temperatures by $20-30^{\circ} \mathrm{C}$ than hot-asphalt mixtures, and far hauling distance [17].

Warm mix asphalt additives (WMAA) kind plays significant role in manufacturing desired binder and mix characteristics. Thus, chosen of WMAA type is importance and depends on bitumen. Different kinds of WMAA are available worldwide, such as natural zeolite (NZ), synthetic zeolite (SZ), sasobit, LEA, Evotherm, Terex-foaming, Cecabase, Asphamin [8].
In one aspect, no process was explored towards using of WMAA in paving construction or rehabilitation in Iraqi projects. In another aspect, aging is preliminary factor influencing the age of an asphalt pavement. Asphalt short- term aging (STA) happen through the production and construction STA stage. Upon aging, the physicochemical characteristicsof the asphalt vary, resulting harder asphalt (i.e. causes cracking failure). Any cracks noticed at the surface of the pavement may exceed the process of aging due to the increased subject to air and result in additional pavement distress, leading to premature paving failures [9].

Few studies have been searched and encouraged on using WMAA in paving application due its environmental and economic benefits. Ivan et.al [10] showed that the mix contained Cecabase exhibited significant improvement against resistance to rutting.

Nishant et.al [11] depicted that using of Evotherm JI in asphalt mixtures minimized the mixing and compaction temperatures of about 
$30^{\circ} \mathrm{C}$ and enhanced the mechanical traits of mixes under aging conditions.

Arega et al. [12] investigated the effect of WMAA and aging on the rheology of four bitumen treated with high and low natural wax dosages, and five WMAA (Evotherm DAT, Evotherm 3G, Sasobit, Rediset WMX, and Cecabase RT 945). It was concluded that the effect of STA on bitumen stiffness depended on bitumen kind and additives. Besides, WMAA may decrease the viscosity of STA binders, especially those treated with higher natural wax dosage.

Xiao et al. [13] performed research to evaluate the effect of STA on the rheological traits of non-foaming WMAA binders. Four binders with four non-foaming WMAA were adopted. It was noticed that the non-foaming WMAA can decrease the bitumen viscosity and thus minimize the mixing and compaction temperatures for the bitumen mix.

However, complimentary studies are needed to give in details more information about other kinds of WMAA and it benefits in improving the rheological and mechanical characteristicsof bitumen under STA effects.

\section{OBJECTIVES OF THE RESEARCH}

The preliminary objectives of this research are to: (1) Compare the rheological and mechanical characteristics of three WMAA (natural zeolite (NZ), synthetic zeolite (SZ) and manufacture zeolite (MZ)) in terms of: penetration, softening point, ductility, elastic recovery, Furol viscosity, elastic modulus, temperature susceptibility, compatibility, cracking index, durability, and shear strength under aging effects; and (2) select the best WMAA among three kinds.

NZ, SZ, and MZ WMAA were chosen for the following reasons: it's convenient for Iraqi climate; and it added to bitumen at lower dosage. For each WMAA kind, one dosage was blended into the 40/50 Dora penetration grade bitumen (D40).

\section{TESTS PROCEDURES}

\subsection{Bitumen and WMAA}

Bitumen utilized in this research was D40 and its physicochemical characteristics were tabulated in Table 1. The results indicated that D40 satisfyASTM [14] and SCRB [15] specifications for penetration graded bitumen.
Table 1:Properties of D40

\begin{tabular}{||c|c|c|c|}
\hline Characteristics & Value & SCRB [15] & ASTM [14] \\
\hline $\begin{array}{c}\text { Penetration }\left(25^{\circ} \mathrm{C}, 100 \mathrm{~g}, 5 \mathrm{~s},\right. \\
\mathrm{dmm}\end{array}$ & 40 & $40-50$ & $40-50$ \\
\hline Softening point, ${ }^{\circ} \mathrm{C}$ & 50 & - & $50-58$ \\
\hline Ductility $\left(25^{\circ} \mathrm{C}, 5 \mathrm{~cm} / \mathrm{min}, \mathrm{cm}\right)$ & $150^{+}$ & $>100$ & $>100$ \\
\hline $\begin{array}{c}\text { Elastic recovery }(\%): \\
\left(25^{\circ} \mathrm{C}\right)\end{array}$ & 81.82 & - & - \\
$\left(15^{\circ} \mathrm{C}\right)$ & 84.85 & - & - \\
\hline Sp. $\operatorname{gr}\left(25^{\circ} \mathrm{C} / 25^{\circ} \mathrm{C}\right)$ & $\begin{array}{c}1.053 \\
2\end{array}$ & - & $1.01-1.06$ \\
\hline Flash point $\left(\mathrm{COC},{ }^{\circ} \mathrm{C}\right)$ & 277 & $>232$ & $>240$ \\
\hline Loss on heat $\left(5 \mathrm{hrs}, 163^{\circ} \mathrm{C}, \%\right)$ & 0.380 & - & $0.2 \mathrm{max}$ \\
\hline P.I. & -1.668 & - & -2 t0 +2 \\
\hline \multicolumn{2}{|r|}{}
\end{tabular}

Three types of WMAA namely: NZ, SZ, and $\mathrm{MZ}$ were selected as chemical additives for D40 at recommended dosages (1.5-3\% wt. of bitumen) by supplier. Physicochemical characteristicsof the WMAA were tabulated in Table 2 and 3.

Table 2: Physicochemical characteristicsof MZ

\begin{tabular}{|l|c||}
\hline \multicolumn{1}{|c||}{ Characteristics } & MZ \\
\hline $\mathrm{C} 31 \mathrm{H} 64, \%$ & 60 \\
\hline $\mathrm{C} 28 \mathrm{H} 58, \%$ & 30 \\
\hline Maltene, \% & 10 \\
\hline Bulk density, g/cc & 0.90 \\
\hline Solubility, \% & Insoluble in water, benzene, and ether \\
\hline
\end{tabular}

Table 3: Physicochemical characteristicsof NZ and SZ

\begin{tabular}{|l|c|c||}
\hline \multicolumn{1}{|c|}{ Characteristics } & NZ & SZ \\
\hline Ingredients & $\begin{array}{c}\text { Na2O.Al2O3. } \\
\text { 2SiO2.27H2O }\end{array}$ & $\begin{array}{c}\text { Na2O.Al2O3. } \\
\text { 2SiO2 }\end{array}$ \\
\hline $\mathrm{SiO} 2, \%$ & 39.46 & 32.8 \\
\hline $\mathrm{Al2O}, \%$ & 28.35 & 29.1 \\
\hline $\mathrm{Na} 2 \mathrm{O}, \%$ & 13.16 & 16.1 \\
\hline $\mathrm{CaO}, \%$ & 0.26 & -- \\
\hline $\mathrm{MgO} \%$ & 0.26 & -- \\
\hline Fe2O3 & 0.84 & -- \\
\hline $\mathrm{K} 2 \mathrm{O}$ & 0.29 & -- \\
\hline L.O.I., \% & 15.13 & 21.2 \\
\hline Surface area, $\mathrm{m}^{2} / \mathrm{g}$ & 7.7 & -- \\
\hline Bulk density, g/cc & 0.730 & 0.568 \\
\hline Water absorption, $\%$ & 18.5 & -- \\
\hline \hline
\end{tabular}

\subsection{D40/WMAA production}

For the production of WMAA binders from $\mathrm{D} 40$, one dosage (1.5\%wt of D40) for each WMAA was mixed under $\left(135 \pm 5^{\circ} \mathrm{C}, 500 \mathrm{rpm}\right.$, and $3 \pm 1$ minutes) conditions to obtain a homogeneous binder. Three modified binders (NZ, SZ, and MZ) were thus produced from D40. 


\subsection{Testing rheological and mechanical characteristics of WMA binders}

The rheological and mechanical tests conducted on WMAA binders (i.e. NZ, SZ, and MZ) before and after STA as per ASTM [14] include: Penetration (D-5); Softening point (D36); Ductility (D-113); Elastic recovery (D3633M); Furol viscosity (D-88); Elastic modulus; Temperature Susceptibility; Compatibility; Cracking characteristics; Durability (STA); and Shear strength (D-5).

\section{RESULTS AND DISCUSSIONS}

\subsection{Penetration and softening point}

Penetration and softening point of WMAA binders before STA were examined and the results are depicted in Figure 1 and 2. The results notify that WMAA are effective in improving D40 characteristics. Penetration at $25^{\circ} \mathrm{C}$, and $46.1^{\circ} \mathrm{C}$ for $\mathrm{NZ}, \mathrm{SZ}$ and $\mathrm{MZ}$ were found to be 37, 41.5, and 46.5, and 203, 209, and 229, respectively. From these results, it can be notified that NZ well done against shear resistance in moderate to high temperatures than other WMAA. As compared with D40, the percent decrease in penetration of $\mathrm{NZ}$ at $25^{\circ} \mathrm{C}$ and $46.1^{\circ} \mathrm{C}$ was noticed to be $7.5 \%$ and $5 \%$, respectively.

The softening point, $\mathrm{R} \& \mathrm{~B}$ traditional test was utilized to examine the high-temperature rutting characteristics of WMAA binders. From Figure 2, R\&B before STA for NZ, SZ and MZ were noticed to be 52,48 , and 46 , respectively. It is shown that NZ exhibited R\&B higher than SZ and MZ. It exhibited 4\% higher R\&B than D40 (i.e. NZ more resistance against rutting than D40, $\mathrm{SZ}$ and MZ). This is because that NZ contains water $\left(27 \mathrm{H}_{2} \mathrm{O}\right)$ in its chemical composition which evaporates during mixing process.

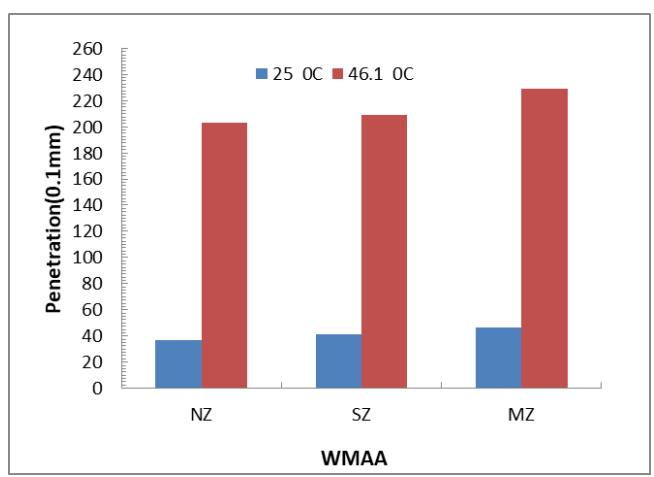

Fig. 1 Penetration of WMAA

\subsection{Ductility and elastic recovery}

The ductility (Du) and elastic recovery (Er) test was performed to examine the elasticity characteristics of WMAA binders. Figure 3 shows $\mathrm{Du}$ at $25^{\circ} \mathrm{C}$ and $15^{\circ} \mathrm{C}$ for WMAA binders. Apparently, different WMAA kinds with the same dosage resulted in different $\mathrm{Du}$ and Er. Testing Figure 3, it can be noticed that all WMAA having $\mathrm{Du}$ values of $100^{+}$at $25^{\circ} \mathrm{C}$ and $15^{\circ} \mathrm{C}$.

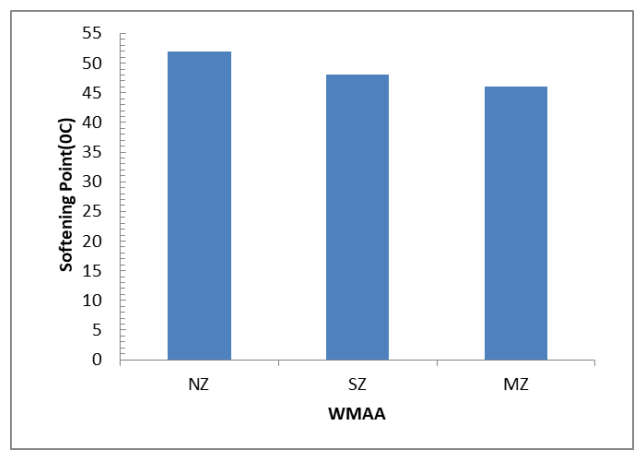

Fig. 2 Softening point of WMAA

Similarly, Er percentage at $25^{\circ} \mathrm{C}$ and $15^{\circ} \mathrm{C}$ for $\mathrm{NZ}, \mathrm{SZ}$, and $\mathrm{MZ}$ were found to be $77 \%$, $79 \%$ and $79 \%$, and $83 \%, 78 \%$ and $84 \%$, respectively. Testing Figure 4 , it can be notified that no significant in $\mathrm{Er}$ values at $25^{\circ} \mathrm{C}$. In contrast, $\mathrm{NZ}$ and $\mathrm{MZ}$ give similar values at $15^{\circ} \mathrm{C}$. These results notify that all WMAA have the same elasticity at medium temperatures, whereas, $\mathrm{NZ}$ and $\mathrm{MZ}$ gives higher elasticity than SZ at $15^{\circ} \mathrm{C}$ (i.e. $\mathrm{NZ}$ and $\mathrm{MZ}$ increase the tensile strain of asphalt-mix layer in flexible pavement).

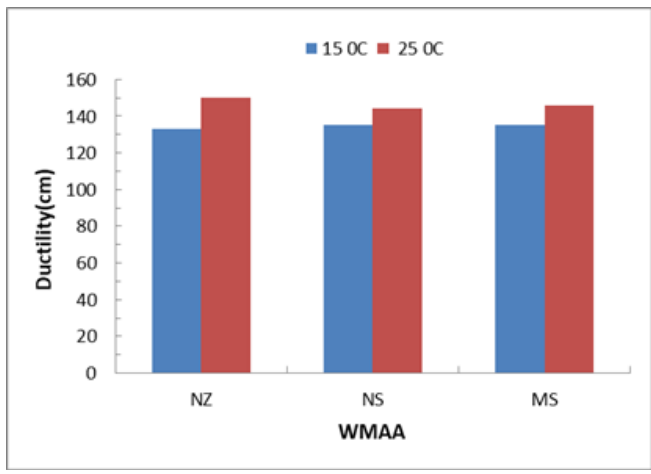

Fig. 3 Ductility of WMAA 


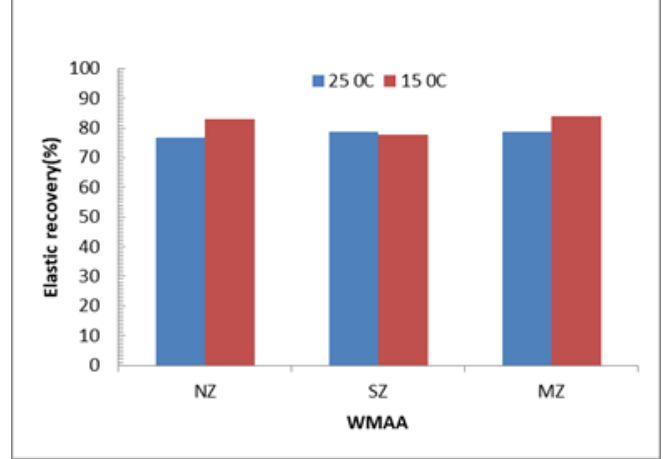

Fig. 4 Elastic recovery of WMAA

\subsection{Furol viscosity}

Furol viscosity (FV) of WMAA binders was examined using Saybolt-Furol viscometer at different temperatures to find out the mixing and compaction temperatures of WMAA mixtures. These temperatures are such that the SayboltFurol viscosities are 85 and $140 \mathrm{~s}$, respectively based on the Asphalt institute manual. Figure 5 depicts the FV. It can be noticed that the addition of WMAA decreases the FV of D40 (i.e. decreases the mixing and compaction temperatures of hot-mix asphalt). It was notified that the addition of NZ, SZ and MZ to D40 reduced the mixing temperatures by 26,22 and $27^{\circ} \mathrm{C}$, respectively, whereas, the compaction temperatures were reduced by 22,20 and $24^{\circ} \mathrm{C}$, respectively. These findings complied with those reported by Ali Topal et.al [16], which illustrated that the mixing and compaction temperatures can be minimized between $20-30^{\circ} \mathrm{C}$.

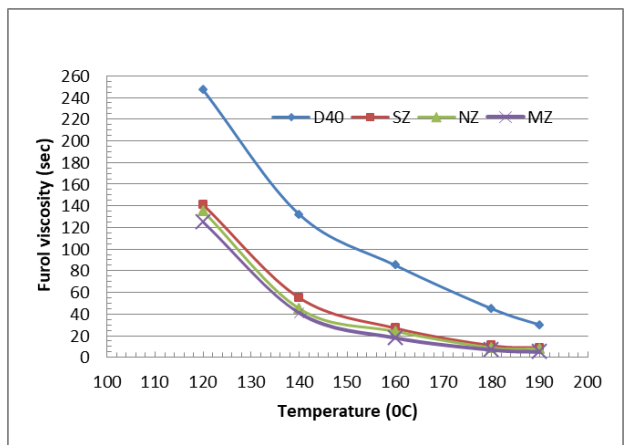

Fig. 5 Furol viscosity of WMAA

\subsection{Elastic modulus}

The elastic modulus (Em) of WMAA binders was calculated based on the binder characteristics utilizing equation 1 as derived from the Van der poelnomograph and as mentioned by Al-Hadidy et.al [18].

$$
\begin{aligned}
& \mathbf{E}_{\mathrm{m}}=1.157 / 10^{7} * \lambda^{-0.368} * 2.718^{- \text {P.I. } *} * \\
& \left(\mathbf{R} \& \mathbf{B}-\mathbf{T}_{\text {binder. }}\right)^{5}(\mathbf{1})
\end{aligned}
$$

Where:

$\mathrm{E}_{\mathrm{m}}=$ the binder elastic modulus $\left(\mathrm{N} / \mathrm{mm}^{2}\right)$,

$\mathrm{R} \& \mathrm{~B}=$ the aged binder softening degree $\left({ }^{\circ} \mathrm{C}\right)$,

$\mathrm{T}_{\text {binder }}=$ the temperature of the binder layer $\left({ }^{\circ} \mathrm{C}\right)$,

P.I. $=$ the agedbinder 'Penetration Index' and

$\lambda=$ the time of loading (sec.).

Equation 1 is only applicable when:

$0.01 \mathrm{sec}<\lambda<0.1 \mathrm{sec}$,

$-1.0<$ P.I. $<1.0$,

$20^{\circ} \mathrm{C}<\left(\mathrm{R} \& \mathrm{~B}-\mathrm{T}_{\text {asp }}\right)<60^{\circ} \mathrm{C}$.

Table 4 shows the Em and WMAA at different temperatures. It was found that the Em values at $40^{\circ} \mathrm{C}$ of $\mathrm{NZ}, \mathrm{SZ}$, and $\mathrm{MZ}$ binder are $0.710,0.155$, and $0.055 \mathrm{Mpa}$, respectively. It can be seen that $\mathrm{NZ}$ binder has higher $\mathrm{Em}$ at $40^{\circ} \mathrm{C}$ than SZ and MZ binders. This indicates that NZ binder is more resistance to rutting and fatigue at high temperatures. Besides, MZ found to have higher $\mathrm{Em}$ at $-10^{\circ} \mathrm{C}$ than $\mathrm{NZ}$ and SZ.

Table 4: Elastic modulus of WMAA

\begin{tabular}{||c|c|c|c|c||}
\hline \multirow{2}{*}{ WMAA } & \multicolumn{4}{|c|}{$\mathrm{Em}, \mathrm{Mpa}$} \\
\cline { 2 - 5 } & $-10^{\circ} \mathrm{C}$ & $10^{\circ} \mathrm{C}$ & $25^{\circ} \mathrm{C}$ & $40^{\circ} \mathrm{C}$ \\
\hline D40 & 3020 & 390 & 38 & 0.389 \\
\hline NZ & 2620 & 374 & 41 & 0.710 \\
\hline SZ & 3870 & 467 & 38 & 0.155 \\
\hline MZ & 3900 & 428 & 29 & 0.055 \\
\hline
\end{tabular}

\subsection{Temperature susceptibility}

The penetration index (P.I.) and penetration ratio (P.R.) equations (2 and 3) [17] were adopted to examine the effect of WMAA addition on temperature susceptibility of D40.

P.I. $=[(\mathbf{2 0 - 5 0 0 A}) /(\mathbf{1}+\mathbf{5 0 A})]$

$\mathrm{A}=[(\log$ pen.@T-log 800)/ (T-R\&B) $]$

P.R. $=\left(\mathbf{P}_{2}\right) /\left(\mathbf{P}_{1}\right)$

Where:

$\mathrm{T}=$ Testing temperature

$\mathrm{R} \& \mathrm{~B}=$ Softening degree.

$\mathrm{P}_{1}$ and $\mathrm{P}_{2}=$ Penetration at $25^{\circ} \mathrm{C}$ and $46.1^{\circ} \mathrm{C}$, respectively.

Figure 6 and 7 shows between the P.I. /P.R. and WMAA. The P.I. values of NZ, SZ, and MZ binder are -1.36, -2.09, and -2.27, respectively. It can be noticed that NZ binder in the normal range of P.I. $(-2.0$ to +2.0$)$. This depicts that NZ binder is less susceptible to temperature varies than SZ and MZ. As well as, the P.R. values of NZ, SZ, and MZ binder are 5.486, 5.036 and 4.925, respectively insure P.I. findings. 


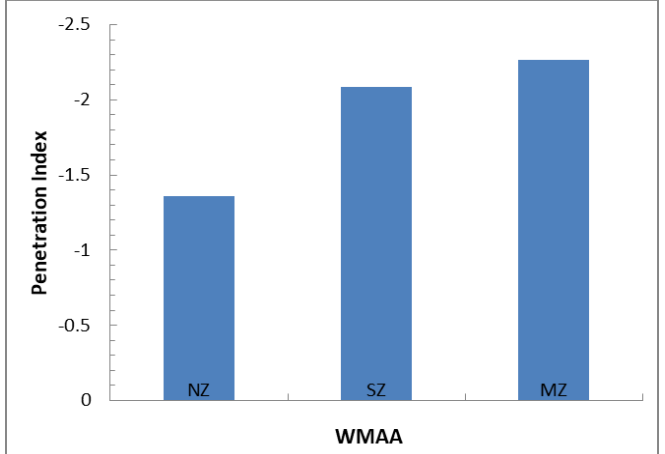

Fig. 6 Penetration index of WMAA

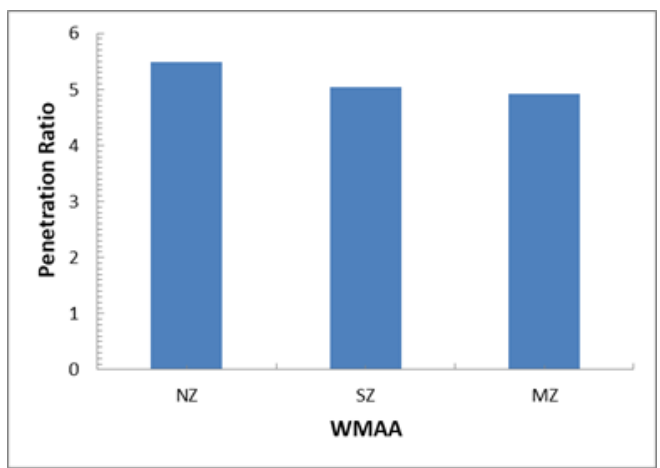

Fig. 7 Penetration ratio of WMAA

\subsection{Compatibility tests}

The compatibility between WMAA and D40 was examined by passing the binder at the mixing temperature of each binder through a $0.075 \mathrm{~mm}$ US sieve. It was noticed that the WMAA binders thus prepared can be stored for future use.

\subsection{Cracking characteristics at low temperatures}

Cracking in flexible pavements cause by thermal influences is effort and non-economic pavements distress in many situations of absolutely cool regions. The reason is primary due to reduction in temperatures, which puts paving materials under tensile stresses (i.e. fracture failure) [17].

Cracking index (CI) described in equation 4 and as reported by Al-Hadidy et.al [17] can be predicted thermal cracking.

$\mathrm{CI}=10.033{ }^{*}$ sq. $\operatorname{root}(\mathrm{AI})+0.334 \log (\mathrm{P})+$

\subsection{8(SP)-166.204}

Where

$\mathrm{AI}=$ aging index,

$\mathrm{P}=$ penetration $\left(25^{\circ} \mathrm{C}\right)$,

$\mathrm{SP}=$ aged binder softening point $\left({ }^{\circ} \mathrm{C}\right)$.

Figure 8 shows the CI for WMAA binders. From this Figure, it was noticed that the
CI values of NZ, SZ, and MZ binder are 32.83, 26.05 , and 30.04 , respectively. This notifies that the NZ and MZ perform better towards thermal cracking effects than SZ due to their higher temperature resistance.

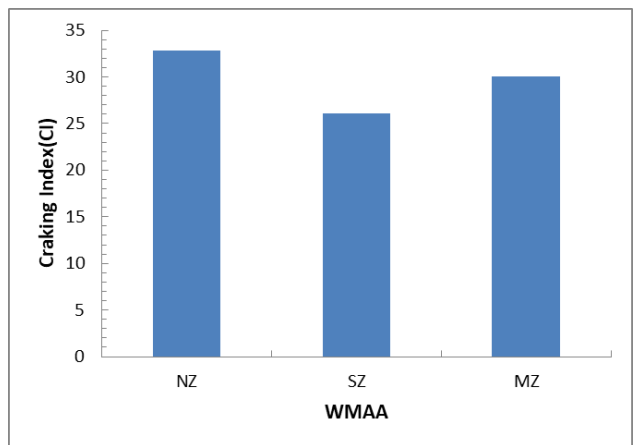

Fig. 8 Cracking index of WMAA

\subsection{Extensional viscosity}

The extensional viscosity $(\lambda b)$ of WMAA binders in Mpa.s was calculated from equation 5 reported by Al-Hadidy et.al $[17,18]$. $\lambda_{b}=3 * 10^{-6}\left\{1.3 * 10^{[3+(} \mathbf{R} \& B^{-T}{ }_{\text {binder }}{ }^{\prime / 10]}\right\}(5)$

Where:

$\mathrm{R} \&$ Band $\mathrm{T}_{\text {binder }}$ (as defined above).

Table 5 shows $\lambda b$ of WMAA binders. It can be noticed that the $\lambda \mathrm{b}$ of NZ, SZ and MZ at $25^{\circ} \mathrm{C} 6.935,7.781$ and $6.18 \mathrm{Mpa} . \mathrm{s}$, respectively. Similarly, these values at $60^{\circ} \mathrm{C}$ were depicted to be $2.19 \times 10-3,2.46 \times 10-3$ and $1.95 \times 10-3$. This depicts that increasing in temperature leads to decrease in binder $\lambda b$.

Table 5:Extensional viscosity of WMAA

\begin{tabular}{|c|c|c||}
\hline \multirow{2}{*}{ WMAA } & \multicolumn{2}{|c|}{$\lambda \mathrm{b}, \mathrm{Mpa} . \mathrm{S}$} \\
\cline { 2 - 3 } & $25^{\circ} \mathrm{C}$ & $60^{\circ} \mathrm{C}$ \\
\hline D40 & 9.796 & $3.09 \times 10^{-3}$ \\
\hline NZ & 6.935 & $2.19 \times 10^{-3}$ \\
\hline SZ & 7.781 & $2.46 \times 10-3$ \\
\hline MZ & 6.18 & $1.95 \times 10^{-3}$ \\
\hline
\end{tabular}

\subsection{Aging (durability) characteristics}

Penetration, Du, SP and Ertests were performed to examine the STA characteristics of the WMAA binders. STA usually occurs in mixing plant and during construction process. A.I was adopted to examine the change in consistency (hardening) of WMAA. A.I was determined from (aged penetration at $25^{\circ} \mathrm{C} /$ virgin penetration at $25^{\circ} \mathrm{C}$ ). Table 6 depicts the test results, including penetration, SP, Du, Er, A.I. and P.I. values measured on WMAA samples after STA. It can be noticed that $\mathrm{SZ}$ binder depicted higher A.I than $\mathrm{NZ}$ and MZ, due to higher bonds between SZ 
additive and $\mathrm{D} 40$, resulting in prevention of the brittleness of the resultant binders (improved STA traits). The Du and Er of aged WMAA binders notifies that $\mathrm{SZ}$ and $\mathrm{MZ}$ binders depicted higher plasticity than $\mathrm{NZ}$ at $15^{\circ} \mathrm{C}$ (i.e., more resistance to deformation). The $\mathrm{Du}$ and $\mathrm{Er}$ at $25^{\circ} \mathrm{C}$ and $15^{\circ} \mathrm{C}$ varied with the type of WMAA. The STA WMAA samples exhibited slight decrease in Er at both tested temperatures. It was found that that all WMAA binders having aged Du values greater than $100 \mathrm{~cm}$ for both tested temperatures, except for $\mathrm{NZ}$ which has $85 \mathrm{~cm}$ Du at $15^{\circ} \mathrm{C}$.

The aged P.I. value of SZ was noticed to be -0.642 and it's at preferable range $(-1.0<$ P.I. $<$ $-0.5)$ as reported in KSLA nomograph [19].

Table 6 shows that the percentage loss in heat and air of NZ, SZ and MZ are 0.010, 0.499 and $0.239 \%$, respectively. It is clear that $\mathrm{NZ}$ and $\mathrm{MZ}$ perform well than SZ against the air and heat effects (i.e. durability of $\mathrm{NZ}$ and $\mathrm{MZ}$ is better than SZ).

Table 6: STA characteristics of WMAA

\begin{tabular}{|c|c|c|c|c|c|c|c|c|c|}
\hline \multirow{2}{*}{$\sum_{3}^{\frac{\pi}{6}}$} & \multirow{2}{*}{$\begin{array}{l}\text { Pen. } \\
\text { dmm }\end{array}$} & \multicolumn{2}{|c|}{$\begin{array}{l}\mathrm{Du}, \\
\mathrm{cm}\end{array}$} & \multicolumn{2}{|c|}{$\mathrm{Er}, \%$} & \multirow{2}{*}{$\begin{array}{l}0 \\
0 \\
\text { in }\end{array}$} & \multirow{2}{*}{$\dot{a}$} & \multirow[b]{2}{*}{$\overline{<}$} & \multirow{2}{*}{ 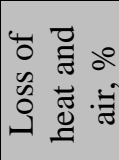 } \\
\hline & & $\stackrel{\text { in }}{\sim}$ & $\begin{array}{l}u \\
i n \\
\sim\end{array}$ & $\begin{array}{l}u \\
i n \\
\sim\end{array}$ & $\begin{array}{l}u \\
\text { in } \\
\rightarrow\end{array}$ & & & & \\
\hline N & $\stackrel{m}{\sim}$ & 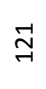 & $\stackrel{\sim}{\infty}$ & $\begin{array}{l}\infty \\
\infty\end{array}$ & $\hat{\infty}$ & $\underset{n}{\stackrel{n}{n}}$ & $\begin{array}{l}\overrightarrow{0} \\
\underset{7}{\rightarrow} \\
\overrightarrow{7}\end{array}$ & $\begin{array}{l}\widetilde{\sigma} \\
0 \\
0\end{array}$ & $\begin{array}{l}\text { m } \\
0 \\
0 \\
0 \\
0\end{array}$ \\
\hline సు & $\stackrel{\infty}{N}$ & $\stackrel{\Im}{\Im}$ & $\stackrel{\infty}{\stackrel{\infty}{\exists}}$ & $\Phi$ & $\begin{array}{l}\infty \\
\infty\end{array}$ & $\stackrel{\infty}{n}$ & 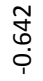 & $\begin{array}{l}\pi \\
\hat{6} \\
0 \\
0\end{array}$ & ণ্ণ \\
\hline$\Sigma^{N}$ & $\vec{N}$ & $\stackrel{\text { ㅇ }}{\rightarrow}$ & $\underset{\sim}{\stackrel{\overbrace{}}{~}}$ & $\stackrel{\infty}{\infty}$ & $\infty$ & in & $\stackrel{\substack{n \\
m \\
\rightarrow-1}}{\rightarrow}$ & 读 & 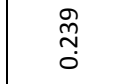 \\
\hline
\end{tabular}

\subsection{Shear strength}

The cone penetration assay (CPA) was introduced to assess the WMA shear strength and as shown in Figure 9. 1:1 wt. ratio of WMAA binder and $\mathrm{CaCO} 3$ as a filler (100 passing $0.075 \mathrm{~mm}$ ) were: (1) blended at the WMAA mixing temperature; (2) WMAA: filler was placed into tin vessel and the later was left in laboratory for $40 \pm 5 \mathrm{~min}$ and then it was cured in water at $30^{\circ} \mathrm{C}$ for $60 \mathrm{~min}$; (3) the CPT was applied on the samples with cone weight (w) of $200 \pm 5 \mathrm{~g}$ until the CPA dial reading ( $\mathrm{h}$ in $\mathrm{dmm}$ ) became stable; and (4) the shear stress $\tau(\mathrm{kPa})$ of WMAA: filler at the inclined cone surface with angle $(\alpha / 2$ $\left.=15^{\circ}\right)$ was calculated using equation 6 : $\tau=\left[981 * w * \cos ^{2}(\alpha / 2)\right] /\left[3.14 * h^{2} * \tan (\alpha / 2)\right](6)$

Triplicate samples were tested for each WMAA kind. Figure 10 depicted that the shear stress of WMAA are of NZ, SZ and MZ are 9.86, 10.88 and $8.15 \mathrm{kPa}$, respectively. It can be noticed that the shear stress of $\mathrm{SZ}$ is better than $\mathrm{NZ}$ and MZ.

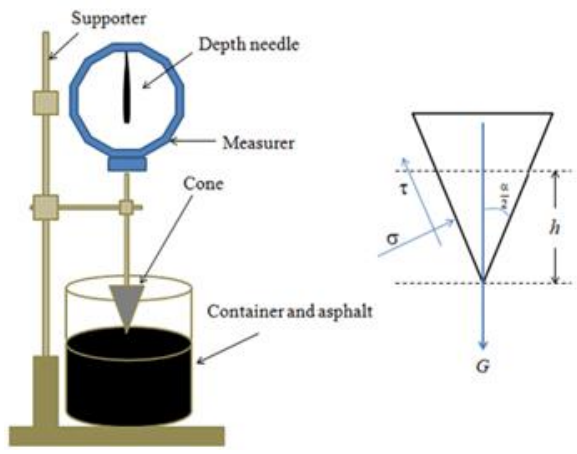

Fig. 9 Shear strength test

Fig. 10Shear strength of WMAA

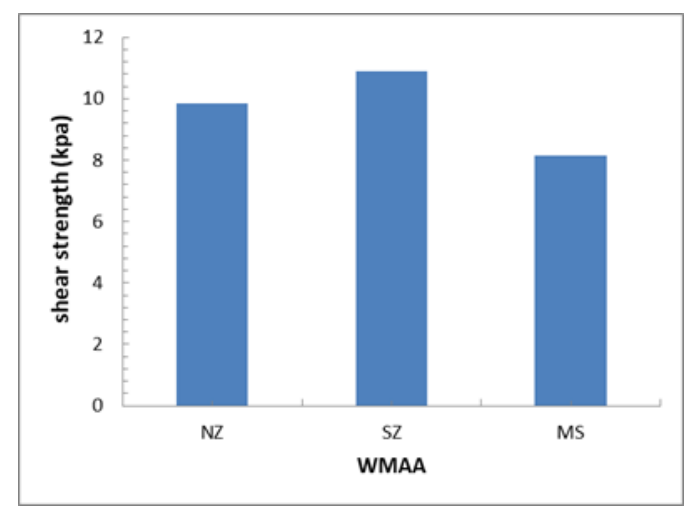

\section{CONCLUSION}

Based on the limited tests performed on WMAA, the following conclusions were documented:

1. NZ perform well against shear and rutting resistance,as well as, it is lesssusceptible to temperature changesthan SZ and MZ. NZ exhibited $7.5 \%$ and $5 \%$ lower penetration at $25^{\circ} \mathrm{C}$ and $46.1^{\circ} \mathrm{C}$, respectively, and $4 \%$ highersoftening points than D40. Besides, NZ is less susceptible to temperature changes than SZ and MZ.

2. The Du and Er results notify that all WMAA have the same elasticity at medium temperatures, whereas, NZ and $\mathrm{MZ}$ gives higher elasticity than $\mathrm{SZ}$ at $15^{\circ} \mathrm{C}$ (i.e. $\mathrm{NZ}$ and $\mathrm{MZ}$ gives more tensile strain for flexible pavement layers). 
3. Addition of NZ, SZ and MZ to D40 reduced the mixing temperatures by 26, 22 and $27^{\circ} \mathrm{C}$, respectively, whereas, the compaction temperatures were minimized to 22 , 20 and $24^{\circ} \mathrm{C}$, respectively.

4. $\mathrm{NZ}$ binder has higher $\mathrm{Er}$ at $40^{\circ} \mathrm{C}$ than SZ and MZ binders. This indicates that $\mathrm{NZ}$ binder is more resistance to rutting and fatigue at high temperatures. Besides, $\mathrm{MZ}$ noticed to have higher $\mathrm{Er}$ at $-10^{\circ} \mathrm{C}$ than NZ and SZ.

5. Compatibility test insures that the prepared WMA binders can be stored for future use.

6. The $\lambda_{b}$,A.I, and shear stress of SZ at $25^{\circ} \mathrm{C}$ and $60^{\circ} \mathrm{Cwas}$ found to be higher than those for NZ and MZ.

7. The Du and Er of aged WMAA binders indicates that SZ and MZ binders noticed higher plasticity than $\mathrm{NZ}$ at $15^{\circ} \mathrm{C}$ (i.e., more resistance to deformation). The aged WMAA samples exhibited slight decrease in $\mathrm{Er}$ at $25^{\circ} \mathrm{C}$ and $15^{\circ} \mathrm{C}$ with aged $\mathrm{Du}$ values greater than $100 \mathrm{~cm}$; and

8. Durability and cracking resistance of $\mathrm{NZ}$ and MZ were noticed to be better than SZ (i.e. more resistance to STA effects).

\section{ACKNOWLEDGEMENTS}

The authors would like to thanks the Muncipality of Mosul for supported this research.

\section{REFERENCES}

[1] West R, Rodezno C, Julian G, Prowell D. Engineering properties and field performance of warm mix asphalt technologies. National Cooperative Highway Research Program, Washington, DC, USA, NCHRP Final Report Project, (09-47A); 2014.

[2] IRC: SP: 101. Interim guidelines for warm mix asphalt. Indian roads congress. New Delhi, India; 2014.

[3] D’Angelo J, Harm E, Bartoszek J, Baumgardner G, Corrigan M, Cowsert J, et al. Warm-Mix Asphalt: European Practice. FHWA-PL08-007; 2008.
[4] FHWA. Warm mix asphalt: European practice. Report of WMA European practice. Federal Highway Administration, Washington, DC, United States; 2008. p. 1924.

[5] BarretoMr, Grampe L, Gonzalez JA. Warm asphalt mixtures by chemical additivation: field and laboratory studies. In: Proceedings of the 4th Eurasphalt\&Eurobitume congress. Copenhagen, Denmark, 2008.

[6] Borleo MBC, Kanitpong K, Charoentham N. Performance evaluation of warm mix asphalt produced with Sasobit additive. In: Proceeding of international conference on road and airfield pavement technology. Sapporo, Japan, 2008.

[7] Hachiya Y, Su K, Motono I, Muranaga T, Kajitani A, Kano T. Implementing overnight asphalt inlay works for rehabilitating full length working runway. In: Proceedings of the 4th Eurasphalt\&Eurobitume congress. Denmark, Copenhagen, 2008.

[8] National Asphalt Pavement Association. (2007). "WMA technologies." Lanham, MD <http://www.warmmixasphalt.com/WmaTec hnologies.aspx> (March 3, 2008).

[9] Ala R. Abbas; MunirNazzal; Savas Kaya; Sunday Akinbowale; BijaySubedi; Mir ShahnewazArefin; and Lana Abu Qtaish (2016). "Effect of Aging on Foamed Warm Mix Asphalt Produced by Water Injection" Journal of Materials in Civil Engineering, 3, 1-11.

[10] Ivan Anwar Syed, Umme A. Mannan and Rafiqul A. Tarefder (2019). "Comparison of rut performance of asphalt concrete and binder containing warm mix additives". International Journal of Pavement Research and Technology 12, 162-169.

[11] NishantBhargava, BhaskarPratim Das, and Anjan Kumar Siddagangaiah (2018). "Synergistic influence of aging and moisture on performance of warm mix asphalt". International Journal of Pavement Research and Technology (article in press).

[12] Arega, Z., Bhasin, A., Motamed, A., and Turner, F. (2011). "Influence of warm-mix additives and reduced aging on the rheology of asphalt binders with different natural wax contents." J. Mater. Civ. Eng., 10.1061/(ASCE)MT.1943-5533.0000315, 1453-1459.

[13] Xiao, F., Amirkhanian, S. N., and Zhang, R. (2012). "Influence of short-term aging on rheological characteristics of non-foaming WMA binders." J. Perform. Constr. Facil., 
10.1061/(ASCE)CF.1943-5509.0000223, $145-152$

[14] ASTM Standard Specifications, (2002). Section 4, 04-03.

[15] State cooperation of road and bridges (SCRB), (1999). "Hot mix asphaltic concrete pavement", Iraqi standard specification, Ministry of Housing and Construction. Department of Design and Study, Section R9.

[16] Ali Topal; Julide Oner; Burak Sengoz; Peyman Aghazadeh Dokandari and Derya Kaya (2017). "Evaluation of Rutting Performance of Warm Mix Asphalt". Int J Civ Eng. Iran University of Science and Technology, DOI 10.1007/s40999-017-01885.

[17] Abdul-Rahim Ibrahim Al-Hadidy, Zeena Ahmed Al-Kazzaz, and Ahmed A.
Mohammed Ali (2020). "Deterministic Extensional Viscosity and Cracking Index of Polypropylene-Modified-Asphalt Binder". Tikrit Journal of Engineering Sciences (2020) 27 (1): 25-29.

[18] Al-Hadidy AI. (2018) "Engineering behavior of aged polypropylene-modified asphalt pavements". J. Construction and Building Materials, (191), 187-192.

[19] Yang, H. (1993). Pavement analysis and design, Prentice-Hall, Upper Saddle River, N.J.

\section{مقارنة الخصائص الريولوجية والميكانيكية لأضافة الزيولات على الأسفلت الافئ تحت ظروف التعتيق ل}

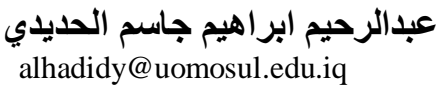

سالم عبدالله خالا

salim733132@gmail.com

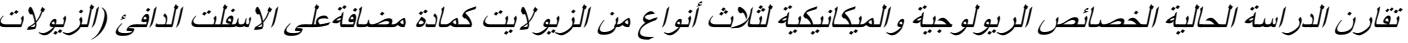

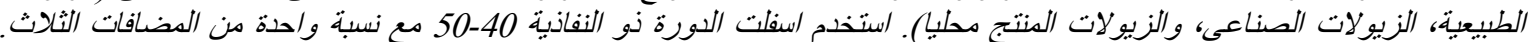

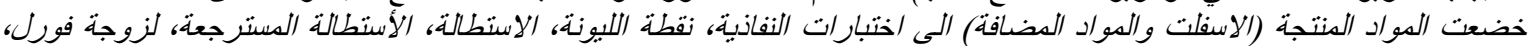

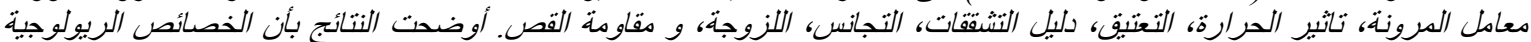

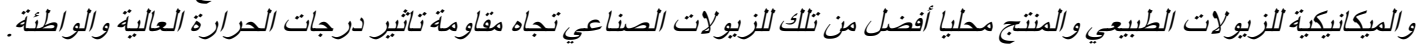

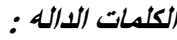

الخصائص الريولوجية، الخصائص الميكانيكية، مضافات لأسفلت الدافئ، التتتبق، مقاومة القص. 